\title{
Influence of Hybridization on Mechanical Properties and Water Absorption in Jute and Jute /E-Glass Reinforced Composites
}

\author{
Vitor da S. Lacerda ${ }^{1, *}$, Ana C. R. da Conceição ${ }^{2}$, Catarina da N. Scherer ${ }^{1}$, Michel G. \\ Santos $^{1}$ and Mirtânia A. Leão ${ }^{1}$ \\ ${ }^{1}$ Federal Institute of Education, Science and Technology of Bahia, Emídio dos Santos St., s/n - Barbalho, \\ Salvador/BA, Zip Code: 40301-015, Brazil \\ ${ }^{2}$ Polytechnic School, Federal University of Bahia, Prof. Aristides Novis St., 2 - Federação, Salvador/BA, Zip \\ Code: 40210-630, Brazil
}

\begin{abstract}
The use of composite materials is increasingly present not only in several industrial areas but also in daily life. With the escalating environmental concern, it is necessary the search for materials that prove to be ecologically sustainable and economically viable. Vegetable fibers have been presenting themselves as an excellent alternative, however, because their disadvantage of having a high moisture absorption capacity, the introduction of synthetic fibers, forming hybrid composites, is a good solution since it combines the characteristics of both types of reinforcements. The present research aims to carry out a comparative study between two types of laminated polymer composites, one reinforced with Jute fibers and the other hybrid, composed of Jute and E-glass fibers. The mechanical performances of the composites submitted to the Uniaxial Tensile, Three-point Flexural and Shear tests were evaluated, as well as fracture analyzes. A comparative study to analyze the influence of hybridization on moisture absorption was carried out. The results showed that the hybridized composite showed an increase in the elastic modulus, as well as in its resistance to flexion and shear, which shows the formation of a more rigid material. Hybridization also changed the moisture content of the composite.
\end{abstract}

Keywords: Jute fibers, polymer composite, hybridization, mechanical properties, water absorption.

\section{INTRODUCTION}

The use of composite materials has been shown to be progressively present in various sectors of the industry, from the highest performances areas such as aerospace and aeronautics, to ordinary areas of our daily lives, such as the automotive and sports equipment sectors. The presence of composites can also be noticed in the naval, construction and energy sectors [1]. Studies focusing on natural fibers have been growing due to their high potential to replace synthetic fibers in reinforcements of polymer composites at a lower cost with increased sustainability [2].

The search for ecologically sustainable and economically viable materials has become increasingly necessary in face of the current environmental situation. The development of a high-performance composite using natural fibers has become a major focus of recent researches, more specifically, finding an alternative for reinforcements with synthetic fibers, considering that they are non-biodegradable materials [3]. Vegetable fibers are advantageous because they

*Address correspondence to this author at the Federal Institute of Education, Science and Technology of Bahia, Emídio dos Santos St., s/n - Barbalho, Salvador/BA, Zip Code: 40301-015, Brazil; Tel: +55 (71) 2102-9481;

E-mail: vitorslacerda85@gmail.com

CODE: BCCM5-046. come from renewable sources and are found abundantly in nature, in addition to having favorable characteristics such as low density, good thermal properties, being less abrasive and also cheaper when compared to synthetic fibers [4]. According to Abdollah et al. [5], the great advantage of using natural fibers is their potential to reduce the weight of the composite by 10 to $30 \%$, due to its low density. This fact leads to higher possibilities for manufacturers to use natural fibers in new products.

The Table 1 shows the mechanical properties of some natural fibers and the glass fiber.

According to Ferreira et al. [6], the vegetable fibers have high water absorption capacity. This characteristic can narrow the application's range of these composites, especially when these materials are exposed to more severe conditions, because they directly influence the mechanical properties of the composite, such as tensile strength and strain rate [7]. According to Filho et al. [1], the composite hybridization is a good solution to avoid problems related to water absorption in natural fibers, since their combination with synthetic ones as a reinforcement in polymeric matrices contributes to the production of a composite material with better properties and lower cost. 
Table 1: Mechanical Properties of Fibers

\begin{tabular}{|c|c|c|c|c|c|c|}
\hline Fibers & $\begin{array}{c}\text { Density } \\
\left(\mathbf{g} / \mathbf{c m}^{\mathbf{3}} \mathbf{)}\right.\end{array}$ & Length $(\mathbf{m m})$ & $\begin{array}{c}\text { Stress } \\
\mathbf{( \% )}\end{array}$ & $\begin{array}{c}\text { Tensile Strength } \\
\mathbf{( M P a})\end{array}$ & $\begin{array}{c}\text { Young's modulus } \\
(\mathbf{G P a})\end{array}$ & $\begin{array}{c}\text { Specific Young's } \\
\mathbf{m o d u l u s}(\mathbf{G P a . c m} \mathbf{m} \mathbf{g})\end{array}$ \\
\hline \hline Ramie & 1.5 & $900-1200$ & $2.0-3.8$ & $400-938$ & $44-128$ & $29-85$ \\
\hline Linen & 1.5 & $5-900$ & $1.2-3.2$ & $345-1830$ & $27-80$ & $18-53$ \\
\hline Hemp & 1.5 & $5-55$ & 1.6 & $550-1110$ & $58-70$ & $39-47$ \\
\hline Jute & $1.3-1.5$ & $1.5-120$ & $1.5-1.8$ & $393-800$ & $10-55$ & $7.1-39$ \\
\hline Sisal & $1.3-1.5$ & 900 & $2.0-2.5$ & $507-855$ & $9,4-28$ & $6,7-20$ \\
\hline Cotton & $1.5-1.6$ & $10-60$ & $3.0-10$ & $287-800$ & $5.5-13$ & $3,7-8,4$ \\
\hline Wool & 1.3 & $38-152$ & $13.2-35$ & $50-315$ & $2.3-5$ & $1,8-3,8$ \\
\hline Glass & 2.5 & Continued & 2.5 & $2000-3000$ & 70 & 29 \\
\hline
\end{tabular}

Glass fibers are the most widely used synthetic fibers in hybrid composites because they provide good results regarding the mechanical properties of the composite, increasing its resistance and elastic modulus, besides its low cost [1].

Jute is a natural fiber and has great potential to replace synthetic fibers because it has specific characteristics that are utterly advantageous, such as high elastic modulus, low elongation and fire resistance [4]. In addition, jute fibers have low density [8].

The hybrid composites represent a large field of study in polymer science. Several industrial sectors are paying special attention to these types of materials as in construction, aeronautics and automotive areas. Hybridization provides the engineer with flexibility to adapt the material properties according to specific requirements [9].

This research aims to compare the mechanical behavior of two materials, one is a hybrid polymer composite reinforced with jute and glass fiber and the other is a composite reinforced with jute. The mechanical performance of the composites submitted to the Uniaxial Tensile, Three-Point Flexural and Shear tests are evaluated and water absorption was analyzed.

\section{MATERIALS AND METHODS}

The laminate is made of bidirectional fabrics of jute and glass fiber which were purchased in the market (Figure 1). The details about the weight of the fabrics, the resin and the curing agent of the laminate are shown in Table 2. All materials were purchased commercially.

In the laminate's manufacturing, two layers of jute fabric with $30 \mathrm{~g}$ and dimensions $335 \times 225 \mathrm{~mm}$ and three layers of glass fiber fabric with $200 \mathrm{~g}$ were used interchangeably, in the same dimensions as the jute layer. The amount of resin used, by weight, was twice the measured value for fibers. The amount of catalyst used was $1 \%$ by weight of the amount of resin. The composite was submitted to hot compression molding, with working temperature of $80{ }^{\circ} \mathrm{C}$ and pressure of 7.8 ton over a period of 1 hour. After compaction, the laminate's final weight was $150 \mathrm{~g}$. The absorption test was performed according to ASTM D 570. The

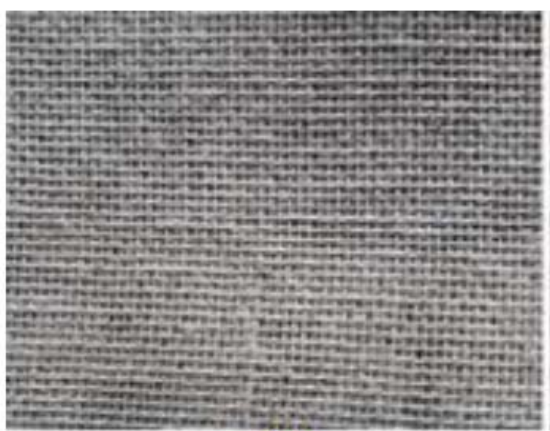

(a)

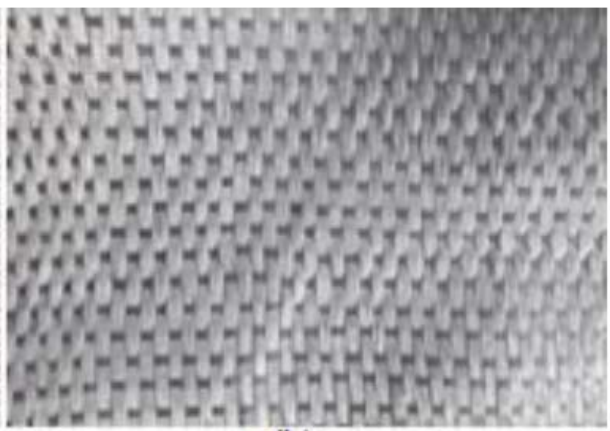

(b)

Figure 1: (a) Bidirectional jute fabric; (b) Bidirectional glass fiber. 
Table 2: Composite Specifications

\begin{tabular}{|c|c|}
\hline Properties & Specifications \\
\hline \hline Gramature & $\begin{array}{c}\text { E-glass: } 225 \mathrm{~g} / \mathrm{m}^{2} \\
\text { Jute: } 118 \mathrm{~g} / \mathrm{m}^{2}\end{array}$ \\
\hline Laminated dimension & $335 \times 225 \mathrm{~mm}$ \\
\hline Matrix & Unsaturated polyester resin Novapol L-120 \\
\hline Manufacturing & Hot compression molding \\
\hline Catalyst & Methyl Ethyl Ketone (MEKP) \\
\hline
\end{tabular}

mechanical behaviour of composites was determined under two condition: in dry state and after water absorption.

The mechanical behavior of composite laminates reinforced by jute (LCJ) and hybrid (LJV) was determined through the Uniaxial Tensile, three-point Flexural and three-point "short beam" Interlaminar Shear Strength (ILSS) tests. All tests were performed at room temperature $\left(25^{\circ} \mathrm{C}\right)$. The tests specifications followed the standards ASTM D3039, ASTM D790 and D 2344/D 2344M [10, 11, 12] for tensile, flexural and shear tests, respectively.

The absorption test was carried out according to ASTM D 570-98 standard, using three samples with 76 x $25 \mathrm{~mm}$ in dimensions in both composites. The test was performed by placing the samples in a container with distilled water at room temperature for 9 days. Before taking them to water, the samples were placed in the oven for 1 hour at $110^{\circ} \mathrm{C}$ to eliminate all humidity absorbed during the manufacturing process. Afterwards, their mass was measured and then immersed in distilled water. Then, the samples were subimitted to same measurement every two hours until the 6th hour, and after that, every 24 hours, up to 216 hours. The comparative study of the moisture absorption of the reinforced composites is showned through a graph.

The macroscopic analysis of fractures aims to evaluate the type of mechanical fracture, its formation and propagation along the length of the sample. The microstructural analysis was performed through optical microscopy and scanning electron microscopy (SEM) and aimed to analyze the influence of the manual manufacturing process on the fiber/matrix interface, in addition to assessing the formation and propagation of damage in the rupture section.

\section{RESULTS}

\subsection{Mechanical Tests}

The response of hybrid and jute-reinforced composites to the uniaxial tensile test is shown in the stress-strain curves (Figure 2) calculated through the average of the results obtained in the test. It is possible to observe the fragile behavior of the composites until the final fracture in both cases.

The average results of the uniaxial tensile tests are shown in Table 3, as well as their standard deviations. The LCJ's ultimate strength showed an average of 4.45 $\mathrm{MPa}$ while the elastic modulus was $0.13 \mathrm{GPa}$. Compared to the hybrid composite which showed an average ultimate strength of $96.64 \mathrm{MPa}$ and elastic modulus of $1.52 \mathrm{GPa}$, the hybrid composite exhibited greater tensile strength, as well as greater elastic modulus compared to LCJ. In addition, it can also be seen that the elongation at break is also bigger in the hybrid composite.

Comparisons of the composite properties can be defined by the ratio of the results between LCJ and LJV. The results show that the hybridization created a boost in the tensile strength of more than $2000 \%$ and in the elastic modulus of more than $1000 \%$, the fracture strain showed a small variation of $0.49 \%$. A better view of this comparison can be seen through the graphs in Figure 3.

The Figure 4 shows the Stress $x$ Displacement curves regarding the interlaminar shear strength test for the samples of jute - reinforced (LCJ) and hybrid (LJV) composites. The average results of the properties, obtained by the interlaminar shear strength test, are shown in Table 4, along with their standard deviations. It is observed that the maximum shear stress for the LJV composite is $18.87 \mathrm{MPa}$, while the LCJ is $5.86 \mathrm{MPa}$, with a boost of more than $200 \%$ in 


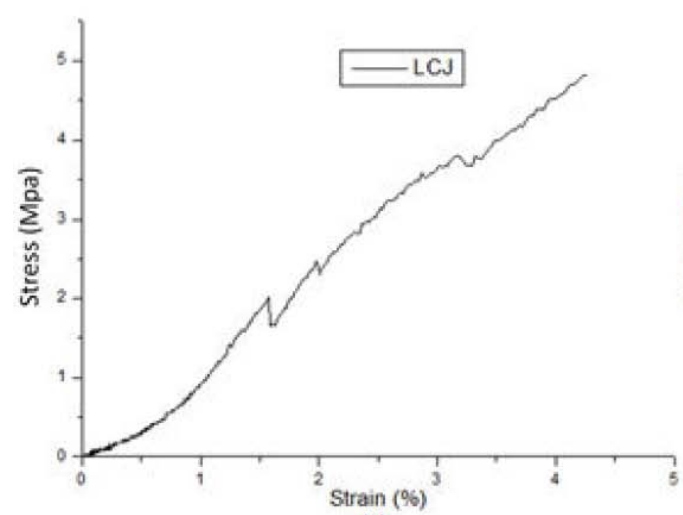

(a)

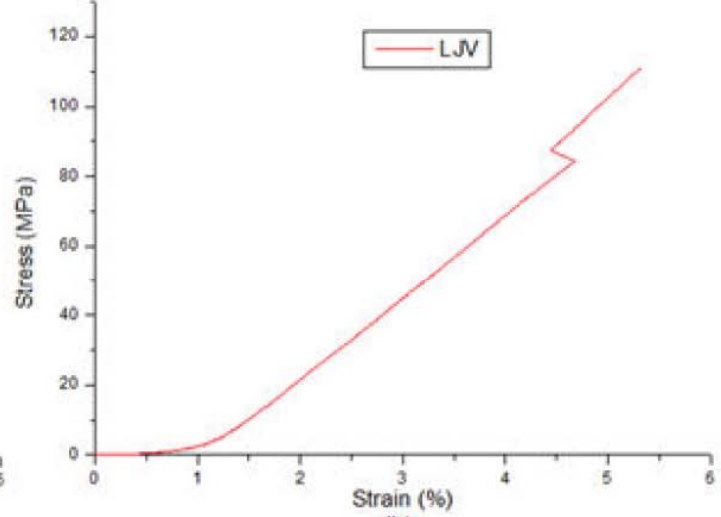

(b)

Figure 2: Uniaxial tensile response (a) LCJ; (b) LJV.

Table 3: Uniaxial Tensile Test Results

\begin{tabular}{|c|c|c|}
\hline Mechanical Properties & LCJ (mean values) & LJV (mean values) \\
\hline \hline Tensile Strength (MPa) & $4.45 \pm 1.20$ & $96.64 \pm 20.65$ \\
\hline Elastic Modulus (GPa) & $0.13 \pm 0.07$ & $1.52 \pm 0.11$ \\
\hline Elongation (\%) & $3.46 \pm 1.56$ & $5.15 \pm 0.28$ \\
\hline
\end{tabular}

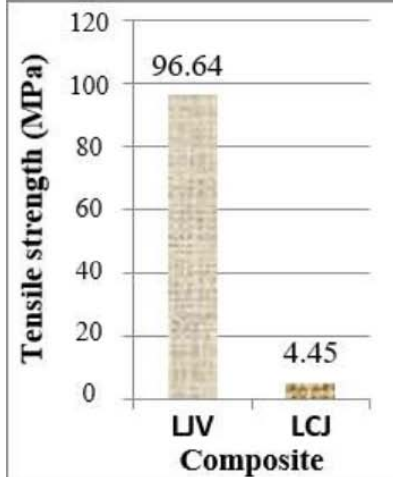

(a)

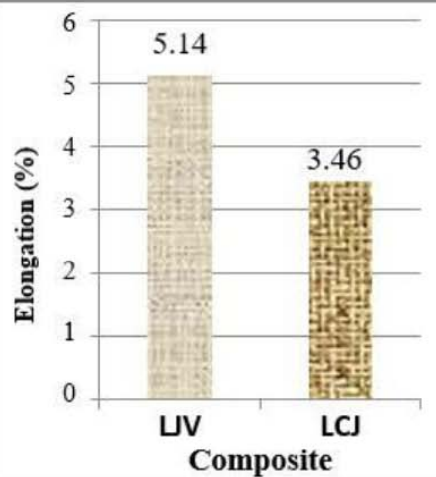

(b)

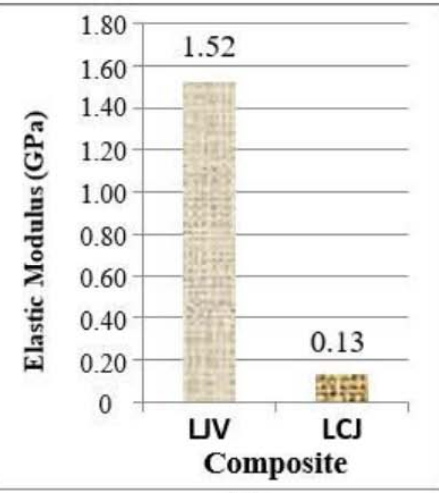

(c)

Figure 3: (a) Tensile strength; (b) Elongation; (c) Elastic Modulus.

this property as consequence of hybridization. Regarding to the maximum displacement, a reduction of approximately $3 \%$ was observed for the hybrid composite when compared to the composite reinforced only by jute due to the greater rigidity of the material caused by the inclusion of the glass fiber.

With the analysis of the flexural results for the studied composites (Figure 5), it is possible to notice the influence of hybridization on the performance of the samples during the test. In the graphical analysis, it is shown that, different from the graph curve of the jute and glass hybrid composite, the graph of the jute composite has a small elastic limit (up to a value close to $4 \mathrm{MPa}$ and $0.01 \%$ deformation), and a slight inclination from this point, having a plastic behavior in most of the test. This somewhat rigid behavior of the LCJ was expected, as according to Table 1, the jute has a low elastic modulus, with Young's modulus varying between 10 and $55 \mathrm{GPa}$.

The composite LJV, in which according to Table $\mathbf{5}$ has an elastic modulus more than 30 times greater than the LCJ, presented a more rigid behavior (curve with little inclination) and more resistance to bending. This performance is due to the addition of the glass fiber to the jute fiber in the polymeric matrix since the hybridization provides the material with an increase in its resistance and elasticity. However, the percentage of maximum deflection of the hybrid composite has a 


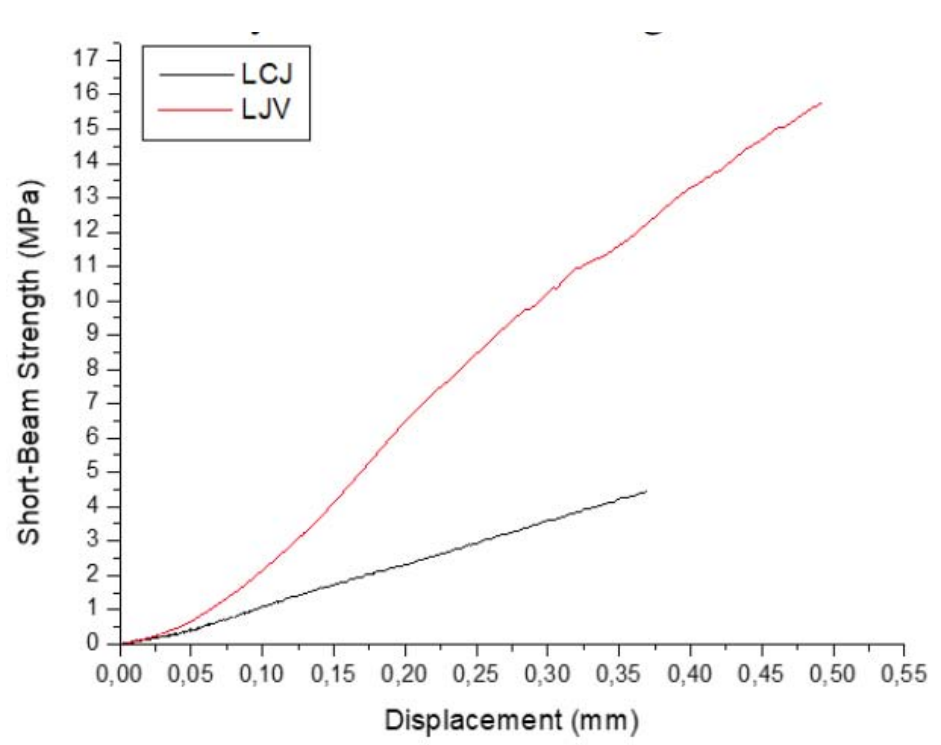

Figure 4: Short-beam curves of the laminates LCJ and LJV.

Table 4: Short-Beam Strength Test Results

\begin{tabular}{|c|c|c|}
\hline Mechanical Properties & LCJ (mean values) & LJV (mean values) \\
\hline \hline Short-beam Strength $(\mathrm{MPa})$ & $5.86 \pm 1.15$ & $18.87 \pm 3.52$ \\
\hline Displacement $(\mathrm{mm})$ & $0.67 \pm 0.23$ & $0.65 \pm 0.12$ \\
\hline
\end{tabular}

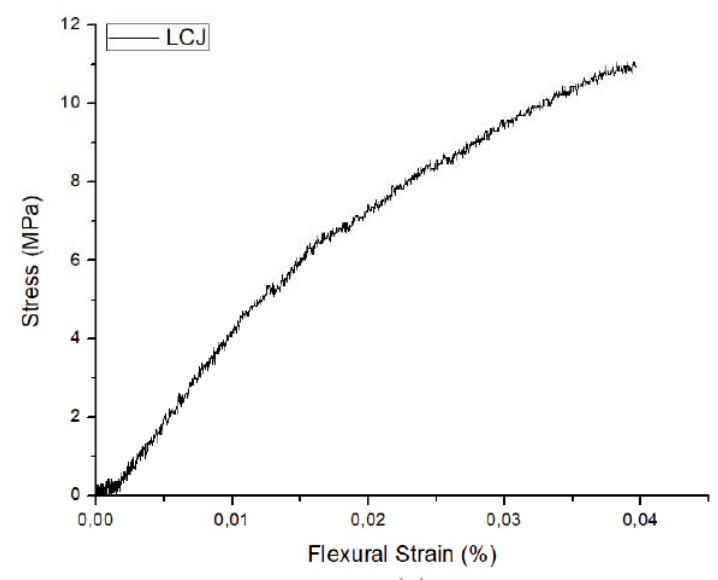

(a)

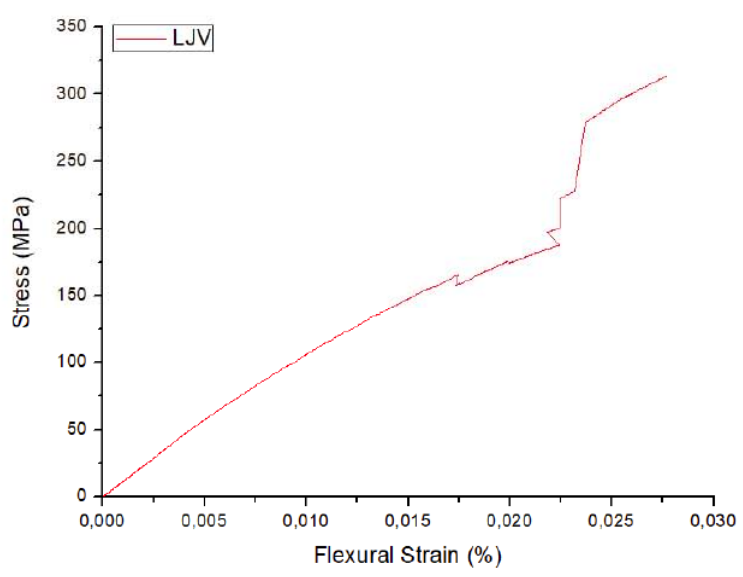

(b)

Figure 5: Three-point flexural curves of the laminates LCJ e LJV (a) LCJ; (b) LJV.

great reduction when compared to the composite reinforced by jute, making this composite to fracture more quickly in certain applications.

\subsection{Absorption Test}

The result of water absorption test is shown in Figure 6.

The composite reinforced by jute showed a mass gain of $13.7 \%$, while the hybrid jute/E-glass composite showed a mass gain of $4.65 \%$. The addition of glass fiber to the composite reduced the water absorption of the laminate by $66 \%$. This behavior occurs because the glass fiber has a low water absorption capacity, and its addition at the ends of the laminate tends to protect the jute fabric from interacting with water, reducing its absorption.

The curve suggests that water absorption follows Fick's law of diffusion, which predicts that the amount of absorbed water increases linearly with the square root of time and eventually stabilizes, reaching 
Table 5: Three-Point Flexural Test Results

\begin{tabular}{|c|c|c|}
\hline Mechanical Properties & LCJ (mean values) & LJV (mean values) \\
\hline Flexural Strengh (MPa) & $11.35 \pm 1.59$ & $201.68 \pm 64.68$ \\
\hline Flexural Modulus (GPa) & $0.25 \pm 0.06$ & $8.74 \pm 2.01$ \\
\hline Flexural Strain (\%) & $0.045 \pm 0.008$ & $0.023 \pm 0.003$ \\
\hline
\end{tabular}

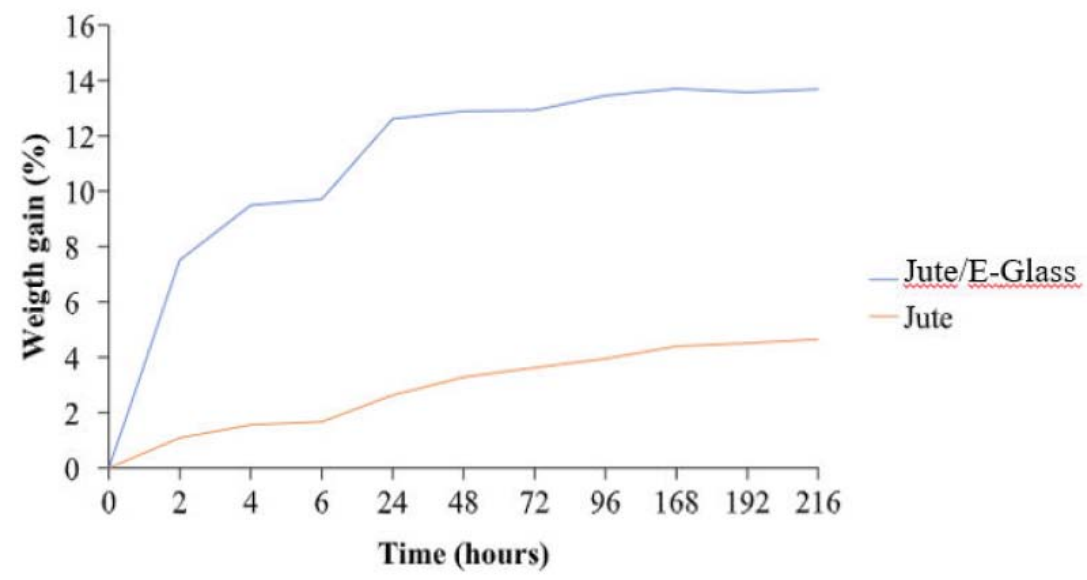

Figure 6: Evolution of wight gain during absorption test.

equilibrium [10]. Fick's law is commonly used to predict the evolution of water absorption over time due to its simplicity and ability to describe the diffusion of water molecules in the composite [11].

\subsection{Fracture Analysis}

Through the optical microscopy (Figure 7) and scanning electron microscopy (Figure 8), we can observe the damage showed in the mechanical tests (uniaxial tensile, three-point Flexural and shear) that are ordinary to polymer composites. Also, in Figure 7, it is possible to see the delamination caused by the shear test.

\section{CONCLUSION}

With this research, it was possible to successfully obtain a hybrid composite of glass fiber and jute fiber in a polyester matrix. In accordance with the initial predictions about the expected results for the association of the main characteristics of these fibers,

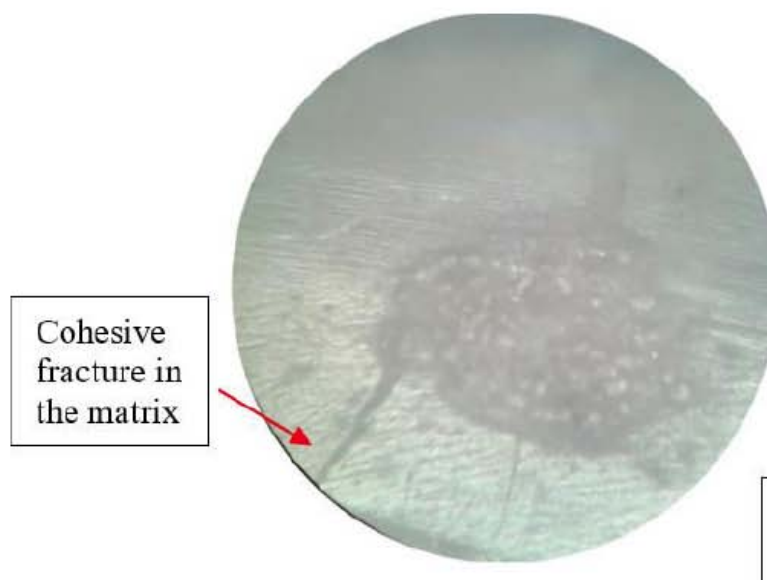

(a)

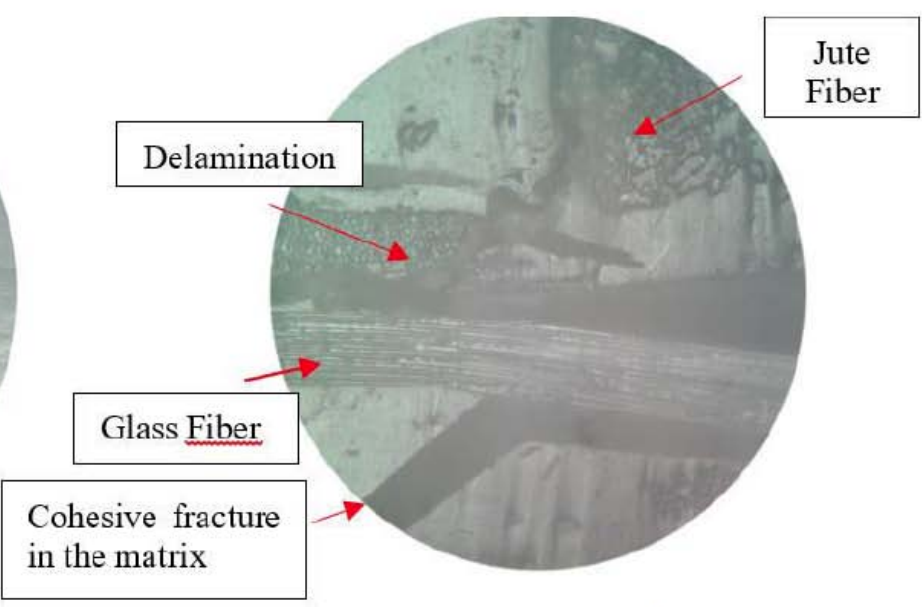

(b)

Figure 7: Analysis by optical microscopy of the laminates LCJ and LJV (a) LCJ; (b) LJV. 


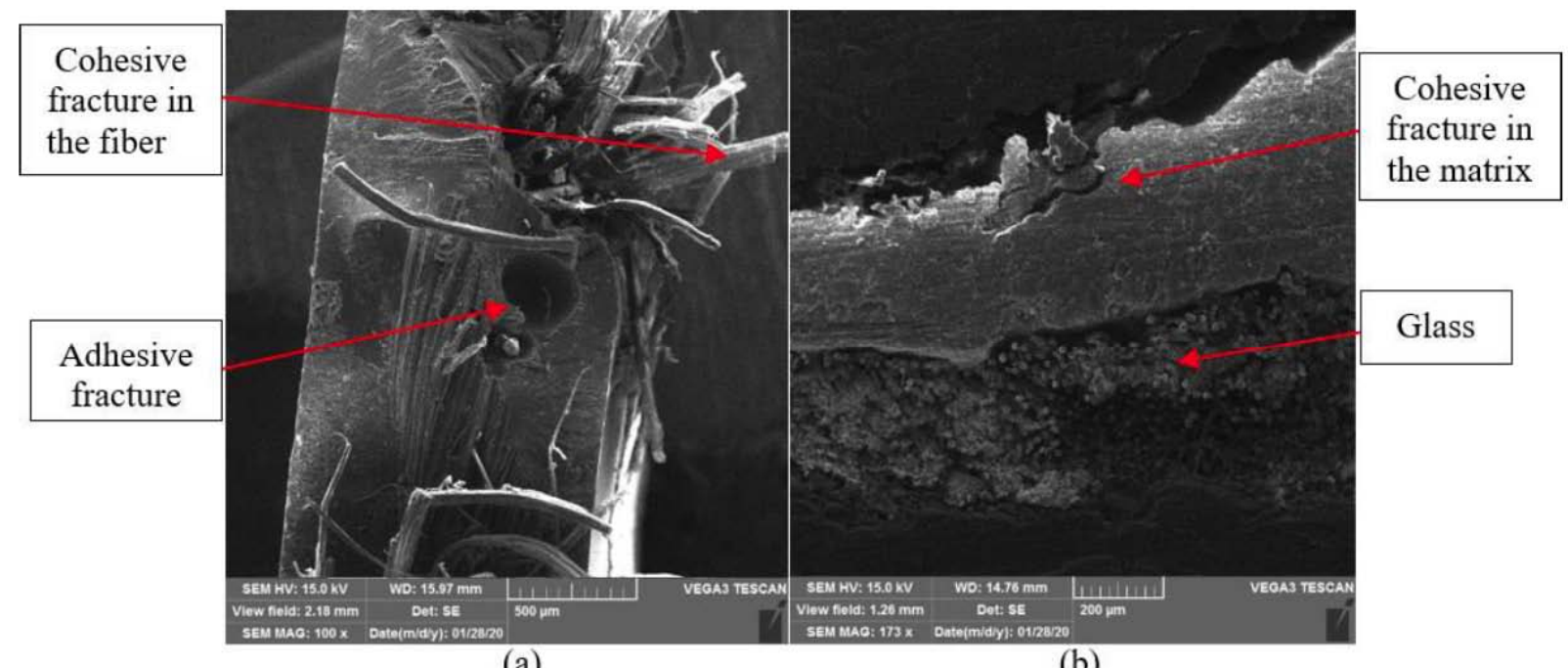

(a)

(b)

Figure 8: Scanning electron microscopy of laminates LCJ and LJV (a) LCJ; (b) LJV.

the hybrid composite presented an excellent mechanical performance in comparison to the composite manufactured only with jute fiber, as shown in the tensile, flexural and shear tests performed in this research. The water absorption test showed that water diffusion in the composite occurs in accordance with Fick's law, with a large increase in weight gain followed by an almost unchanging weight variation after 96 hours. There was less moisture absorption by the hybridized composite due to the addition of the glass fiber. Regarding the fractures, the defects were in agreement with what was expected in the standards for these types of materials and tests used, but with emphasis on a greater adhesion of the jute fiber to the matrix, when it is compared to the adhesion of other natural fibers to their respective matrices, as presented in other research projects.

\section{ACKNOWLEDGEMENTS}

The authors would like to thank the Federal Institute of Bahia IFBA/PRPGI for the financial support during this research project.

\section{RESPONSIBILITY NOTICE}

The authors are the only responsible for the printed material included in this paper.

\section{REFERENCES}

[1] Filho GCO, Mota RCS, Conceição ACR, et al. Effects of hybridization on the mechanical properties of composites reinforced by piassava fibers tissue. Composites Part B 2019; 162: 73-79. https://doi.org/10.1016/j.compositesb.2018.10.050

[2] Pickering KL, Efendy MA, Le TM. A review of recent developments in natural fibre composites and their mechanical performance. Composites Part A 2016; 83: 98112.

https://doi.org/10.1016/j.compositesa.2015.08.038

[3] Gopinath A, Kumar MS, Elayaperumal A. Experimental investigations on mechanical properties of jute fiber reinforced composites with polyester and epoxy resin matrices. Procedia Engineering 2014; 97: 2052-2063. https://doi.org/10.1016/j.proeng.2014.12.448

[4] Raghavendra G, Kumar KA, Kumar $\mathrm{MH}$, et al. Moisture absorption behavior and its effect on the mechanical properties of jute-reinforced epoxy composite. Polymer Composites 2017; 38: 516-522. https://doi.org/10.1002/pc.23610

[5] Abdollah MFB, Shuhimi FF, Ismail N, et al. Selection and verification of kenaf fibres as an alternative friction material using Weighted Decision Matrix method. Materials \& Design 2015; 67: 577-582. https://doi.org/10.1016/j.matdes.2014.10.091

[6] Ferreira JM, Capela C, Manaia J, et al. Mechanical Properties of Woven Mat Jute/Epoxy Composites. Materials Research 2016; 19(3): 702-710.

https://doi.org/10.1590/1980-5373-MR-2015-0422

[7] Venkatesh RP, Ramanathan K, Raman VS. Tensile, flexual impact and water absorption properties of natural fibre reinforced polyester hybrid composites. Fibres \& Textiles 2016; 24: 90-94. https://doi.org/10.5604/12303666.1196617

[8] Memon A, Nakai A. Fabrication and mechanical properties of jute spun yarn/PLA unidirection composite by compression molding. Energy Procedia 2013; 34: 830-838. https://doi.org/10.1016/j.egypro.2013.06.819

[9] Romanzini D, Lavoratti A, Ornaghi HL Jr, et al. Influence of fiber content on the mechanical and dynamic mechanical properties of glass/ramie polymer composites. Materials \& Design 2013; 47: 9-15.

https://doi.org/10.1016/j.matdes.2012.12.029

[10] Boukettaya S, Alawar A, Almaskari F, et al. Modeling of water diffusion mechanism in polypropylene/date palm fiber composite materiais. Journal of Composite Materials 2018; 52(19): 2651-2659. https://doi.org/10.1177/0021998317752228

[11] de Brito MKT, dos Santos WRG, de B. Correia BR, et al. Moisture absorption in polymer composites reinforced with vegetable fiber: a three-dimensional investigation via Langmuir model. Polymers 2019; 11: 1847. https://doi.org/10.3390/polym11111847 
[12] American Society for Testing and Materials - D790-02. Standard Test Method for Flexural Properties of Unreinforced and Reinforced Plastics and Electrical Insulating Materials. EUA 2002.

[13] American Society for Testing and Materials D2344/D2344M-00. Standard Test Method for Short-Beam Strength of Polymer Matrix Composite Materials and Their Laminates. EUA 2000.
[14] American Society for Testing and Materials - 3039/D3039 M08-00. Standard Test Method for Tensile Properties of Polymer Matrix Composite Materials. EUA 2008.

[15] American Society for Testing and Materials - D570-98. Standard Test Method for Water Absorption of Plastics. EUA 2010.

Received on 25-01-2021

https://doi.org/10.6000/1929-5995.2021.10.2

(C) 2021 Lacerda et al.; Licensee Lifescience Global.

This is an open access article licensed under the terms of the Creative Commons Attribution Non-Commercial License (http://creativecommons.org/licenses/by-nc/3.0/) which permits unrestricted, non-commercial use, distribution and reproduction in any medium, provided the work is properly cited. 